\title{
ANALISIS BAHASA INDONESIA PADA LAPORAN HASIL KEGIATAN PENERAPAN PERANGKAT PEMBELAJARAN (P3)
}

\author{
Luci Fitri $^{1}$, Didi Yulistio ${ }^{2}$, Gumono $^{3}$ \\ Universitas Bengkulu ${ }^{1,2,3}$ \\ $\underline{\text { lucifitri01@gmail.com }}$
}

Submit, 28-09-2019 Accepted, 27-12-2019 Publish, 27-12-2019

\begin{abstract}
ABSTRAK
Penelitian ini bertujuan untuk mendeskripsikan penggunaan bahasa Indonesia pada Laporan Hasil Kegiatan Penerapan Perangkat Pembelajaran (P3) Mahasiswa Program Studi Bahasa dan Sastra Indonesia STKIP PGRI Lubuklinggau. Metode penelitian yang digunakan adalah metode kualitatif dengan jenis penelitian deskriptif kualitatif. Teknik pengumpulan data pada penelitian ini dengan teknik dokumentasi. Teknik analisis data dengan cara reduksi data, penyajian data, dan kesimpulan. Hasil penelitian menunjukan bahwa Analisis bahasa Indonesia pada Laporan Hasil Kegiatan Penerapan Perangkat Pembelajaran (P3) terdapat kesalahan pada penggunaan ejaan dalam penelitian ini didapatkan sebanyak 831 kutipan data. Kesalahan pemilihan kata dalam penelitian ini didapat sebanyak 366 kutipan data.Kalimat yang tidak efektif didapatkan sebanyak 516 kutipan data. Berdasarkan hasil penelitian dapat disimpulkan jika penggunaan Bahasa Indonesia pada hasil laporan P3 (Penerapan Perangkat Pembelajaran) masih kurang, sehingga memerlukan bimbingan lebih lanjut agar kedepanya penggunaan bahasa Indonesia bisa lebih baik.
\end{abstract}

Kata Kunci: Analisis Bahasa, Laporan, Penerapan Perangkat Pembelajaran (P3)

\section{ABSTRACT}

This study aims to describe the use of Indonesian in the Report on the Activities of the Application of Learning Tools (P3) of Indonesian Language and Literature Study Program Students STKIP PGRI Lubuklinggau. The research method used is a qualitative method with the type of descriptive qualitative research. Data collection techniques in this study were documentation techniques. Data analysis techniques by data reduction, data presentation, and conclusions. The results showed that the analysis of the Indonesian language in the Learning Activity Application Reports (P3) there were errors in the use of spelling in this study as many as 831 data quotations were obtained. Word selection errors in this study were 366 citations of data obtained. Ineffective Kalimat obtained 516 citations of data. Based on the results of the study it can be concluded if the use of Indonesian in the P3 report (Application of Learning Tools) is still lacking, so that further guidance is needed so that the future use of Indonesian can be better.

Keywords: Language Analysis, Reports, Application of Learning Tools (P3) 


\section{PENDAHULUAN}

Bahasa merupakan salah satu alat untuk berinteraksi atau berkomunikasi berupa lambang bunyi yang dihasilkan alat ucap manusia, untuk menyampaikan pikiran atau gagasan, konsep atau perasaan seseorang. Dalam berkomunikasi, baik lisan maupun tulisan, seseorang menggunakan keterampilan berbahasa yang telah dimiliki, meskipun setiap orang memiliki tingkatan atau kualitas yang berbeda-beda. Berdasarkan penjelasan tersebut bahasa Indonesia merupakan faktor utama dalam berkomunikasi, serta dapat mengevaluasi keterampilan seseorang terhadap kemampuan menggunakan bahasa Indonesia. Selain itu juga bahasa Indonesia sangat berpengaruh penting dalam proses pembelajaran, baik di sekolah maupun di perguruan tinggi.

Analisis penggunaan bahasa Indonesia digunakan pada laporan hasil kegiatan P3 (Penerapan Perangkat Pembelajaran) mahasiswa. Laporan kegiatan adalah suatu laporan yang didasarkan hasil penelitian, baik pada penelitian lapangan, laboratories maupun penelitian pustaka (Ayudia, et.al. 2016). Jadi, laporan hasil kegiatan merupakan salah satu jenis laporan penelitian. Suatu penulisan laporan yang baik terlebih dahulu harus memiliki bahasa yang baik dan pada setiap aspek yang disampaikan dalam penulisan juga harus sesuai dengan apa yang telah dilakukan dalam pengamatan.Penulisan laporan kegiatan diawali dengan melaksanakan pengamatan, hal ini agar hasil tulisan semakin terpercaya.

Fokus penelitian ini yaitu analisis penggunaan bahasa Indonesia pada laporan hasil kegiatan P3 (Penerapan Perangkat Pembelajaran). Sedangkan sub fokus penelitian yaitu analisis penggunaan bahasa Indonesia meliputi ejaan, bentuk dan pemilihan kata, dan kalimat. Analisis penggunaan ejaan yang baku sangat berpengaruh penting dalam penulisan laporan kegiatan. Karena dalam penggunaan bahasa yang baik dan benar sesuai dengan EYD (Ejaan Yang Disempurnakan) bahasa bukan hanya sekedar berkomunikasi, berbahasa perlu menaati kaidah-kaidah atau aturan bahasa yang berlaku.peneliti menganalisis penggunaan bahasa Indonesia yaitu untuk mengetahui EYD yang digunakan pada laporan hasil kegiatan P3 (Penerapan Perangkat Pemebalajaran)mahasiswa semester VIIA ini sudah tepat atau tidaknya.

Chaer (2016) menjelaskan penggunaan bahasa Indonesia adalah pengunaan bahasa yang menggunakan kaidah dan ketepatan memilih ragam yang sesuai dengan kebutuhan komunikasi. Ejaan bahasa Indonesia yang disempurnakan adalah ejaan yang 
berpedoman pada buku Pedoman Umum Ejaan Bahasa Indonesia Yang Disempurnakan yang disalin dari Pusat Pembinaan Dan Pengembangan Bahasa Departemen Pendidikan Nasional Republik Indonesia serta berdasarkan Peraturan Menteri Pendidikan Nasional Republik Indonesia Nomor 46 tahun 2009. Ruang lingkup Ejaan Yang Disempurnakan (EYD) mencakup lima aspek, yaitu: 1) Pemakaian huruf, 2) Penulisan huruf, 3) Penulisan kata, 4) Penulisan unsur serapan, dan 5) Pemakaian tanda baca (Yustisia, 2015).

Penelitian ini relevan dengan penelitian Ayudia et.al (2016) menjelaskan hasil penelitian diketahui hasil laporan observasi siswa SMP masih kurang berkaitan dengan penggunaan ejaan, diksi, kalimat dan paragraf. Selanjutnya Utomo, (2019) menjelaskan ditemukan kesalahan bahasa dalam penggunaan diksi, frasa, dan ketidak efektifan kalimat, dan lebih dominan pada penggunaan kata baku dan tidak baku. Selain itu Ramaniyar, (2019) menjelaskan hasil penelitian menunjukan kesalahan ejaan berupa penulisan kata, pemakaian huruf, penulisan judul, penulisan latar belakang dan bagian kesimpulan.

Namun dalam penelitian ini lebih menitik beratkan pada kesalahan pekaian ejaan meliputi ejaan, kata, dan kalimat efektif pada laporan hasil kegiatan P3 (Penerapan Perangkat Pembelajaran) mahasiswa program studi pendidikan bahasa dan sastra Indonesia, kemudian lebih mengarah pada penggunaan ejaan bahasa Indonesia

\section{METODE PENELITIAN}

Metode yang peneliti gunakan adalah metode deskriptif kualitataif. Penelitian deskriptif juga dilaksanakan untuk mengembangkan tujuan yang luas dari ilmu yang mendasari masalah dan penjelasan. Objek analisis adalah laporan kegiatan P3 mahasiswa Program Studi Pendidikan Bahasa dan Sastra Indonesia STKIP PGRI Lubuklinggau. Peneliti mengumpulkan data, mencatat data, dan menganalisis untuk menafsirkan data yang ada. Instrumen ini berupa alat pengumpul data sebenarnya, yang menjadi instrumen atau alat penelitian adalah peneliti sendiri. Oleh karena itu, peneliti perlu membuat alat pengumpul data berupa pedoman pencatatan dokumen. 
Tabel 1

Kisi-Kisi Pencatatan Dokumen Laporan Kegiatan.

\begin{tabular}{lll}
\hline \multirow{2}{*}{ No } & Aspek Bahasa Indonesia Laporan Hasil Kegiatan & \multicolumn{1}{c}{ Indikator } \\
\hline $\mathbf{1}$ & Penggunaan Ejaan & Huruf \\
& & Kata \\
& & Unsur Serapan \\
& & Tanda Baca \\
\hline $\mathbf{2}$ & Penggunaan Kata & Kata Dasar \\
& & Kata depan \\
\hline $\mathbf{3}$ & Penggunaan Kalimat & Kalimat Efektif \\
\hline
\end{tabular}

\section{HASIL PENELITIAN}

Penelitian ini dilakukan pada hasil laporan kegiatan Penerapan Perangkat pembelajaran mahasiswa, untuk menganalisis data ada beberapa tahapan yaitu membaca dan memeriksa ketidaktepatan analisis bahasa Indonesia pada hasil laporan kegiatan Penerapan Perangkat Pembelajaran (P3) mahasiswa Program Studi Pendidikan Bahasa dan Sastra Indonesia STKIP-PGRI Lubuklinggau, mencari analisis bahasa Indonesia pada huruf dan tanda bacanya yang ada pada hasil laporan kegiatan Penerapan Perangkat Pembelajaran(P3) mahasiswa.

Pada penggunaan bahasa Indonesia terdapat kesalahan penggunaan ejaan sebesar 831 kutipan data, penggunaan pemilihan kata sebanyak 327 kutipan data dan penggunaan kalimat sebanyak 516 kutipn data. Di antara penggunaan bahasa Indonesia penggunaan ejaan lebih banyak kesalahannya karena, penggunaan pemilihan kata data yang terkecil karena kesalahan pada pemilihan kata sebesar 366 kutipan data dan penggunaan kalimat pada kalimat efektif kesalahan yang sedang sebanyak 516 kutipan data, memiliki kesalahanan yang dominan. Berikut yang dapat disampaikan beberapa faktor yang menyebabkan kesalahanan pada penggunaan ejaan, penggunaan pemilihan kata dan penggunaan kalimat dengan presentasi terbesar dan terkecil.

Berdasarkan ke-22 data mahasiswa terdapat penggunaan bahasa Indonesia yang kesalahan terbesar dan terkecil. Berdasarkan data tersebut, berikut penelitian yang telah dilakukan oleh penulis terhadap penggunaan bahasa Indonesia pada penggunaan ejaan, penggunaan pemilihan kata dan penggunaan kalimat. 
Tabel 2

Hasil Analisis Ejaan Bahasa Indonesia pada Hasil Laporan Kegiatan Penerapan Perangkat Pembelajaran (P3)

\begin{tabular}{|c|c|c|c|c|c|c|c|c|c|c|c|c|c|c|c|c|}
\hline \multirow{3}{*}{ No } & \multirow{3}{*}{ Data } & \multicolumn{13}{|c|}{ Ejaan Bahasa Indonesia } & \multirow{3}{*}{ Jml } & \multirow{3}{*}{ Ket } \\
\hline & & \multicolumn{3}{|c|}{ Huruf } & \multicolumn{6}{|c|}{ Tanda Baca } & \multicolumn{4}{|c|}{ Unsur Serapan } & & \\
\hline & & HK & HM & HB & TT & TK & TH & TT & GM & TY & $\mathbf{A A}$ & AO & $\mathbf{T}$ & $\mathbf{P}$ & & \\
\hline 1 & D1 & 7 & 2 & 7 & 2 & 1 & 10 & 1 & 3 & 7 & 8 & 7 & 9 & 1 & 65 & \\
\hline 2 & D2 & 6 & 1 & 4 & 2 & 7 & 5 & 6 & 1 & - & 9 & 8 & 4 & - & 53 & \\
\hline 3 & D3 & 4 & - & 2 & 5 & 2 & 1 & 10 & 8 & 2 & 4 & 3 & 3 & - & 44 & \\
\hline 4 & D4 & 1 & 1 & 1 & 1 & 2 & 4 & 9 & 1 & - & 5 & 1 & 4 & - & 30 & \\
\hline 5 & D5 & 5 & 2 & 2 & - & 2 & 3 & 11 & 1 & - & 7 & 2 & 2 & - & 37 & \\
\hline 6 & D6 & 4 & 2 & 2 & 2 & 2 & 4 & 6 & 2 & - & 4 & 5 & - & - & 33 & \\
\hline 7 & D7 & 3 & 2 & 2 & - & 3 & 7 & 6 & 2 & - & 3 & 10 & 3 & - & 41 & \\
\hline 8 & D8 & 2 & 1 & 1 & 1 & - & 4 & 5 & 2 & - & 10 & 7 & - & - & 33 & \\
\hline 9 & D9 & 3 & 1 & - & - & 2 & 4 & 7 & 5 & - & 8 & 5 & - & - & 35 & \\
\hline 10 & D10 & 5 & - & 1 & 1 & - & 4 & 5 & 1 & 1 & 16 & 4 & - & - & 38 & \\
\hline 11 & D11 & 4 & - & 1 & - & - & 1 & 6 & 2 & 1 & 9 & 1 & - & - & 25 & \\
\hline 12 & D12 & 10 & 4 & 3 & 2 & - & 4 & 5 & 1 & - & 8 & 1 & - & - & 38 & \\
\hline 13 & D13 & 2 & 1 & 1 & - & 3 & 5 & 7 & 4 & - & 8 & 3 & - & - & 34 & \\
\hline 14 & D14 & 8 & 4 & 5 & - & 2 & 5 & 6 & 6 & - & 9 & 5 & - & - & 50 & \\
\hline 15 & D15 & 7 & 2 & 2 & 1 & 1 & 3 & 4 & 2 & 2 & 7 & 3 & 1 & - & 35 & \\
\hline 16 & D16 & 4 & 1 & 2 & 2 & 1 & 3 & 5 & 1 & - & 6 & 2 & - & - & 27 & \\
\hline 17 & D17 & 2 & 3 & 1 & 1 & - & 3 & 5 & 1 & 1 & 10 & 4 & 2 & - & 33 & \\
\hline 18 & D18 & 4 & 2 & 2 & 1 & - & 3 & 5 & 1 & - & 6 & 1 & 2 & - & 27 & \\
\hline 19 & D19 & 3 & 1 & - & 2 & - & 4 & 4 & - & - & 8 & 4 & 1 & - & 27 & \\
\hline 20 & D20 & 2 & 3 & - & 1 & - & 2 & 5 & 2 & - & 10 & 1 & - & - & 26 & \\
\hline 21 & D21 & 2 & 4 & 2 & 1 & - & 4 & 6 & 3 & - & 6 & 1 & 5 & - & 34 & \\
\hline 22 & D22 & 2 & 3 & 1 & 1 & 1 & 4 & 4 & - & - & 9 & 1 & 2 & - & 28 & \\
\hline \multicolumn{2}{|c|}{ Jumlah } & 87 & 40 & 41 & 25 & 28 & 83 & 124 & 49 & 14 & 170 & 79 & 38 & 1 & 779 & \\
\hline
\end{tabular}

Tabel 3

Hasil Analisis Penulisan Kata Bahasa Indonesia padaHasil Laporan Kegiatan Penerapan Perangkat Pembelajaran (P3)

\begin{tabular}{|c|c|c|c|c|c|}
\hline \multirow{2}{*}{ No } & \multirow{2}{*}{ Data } & \multicolumn{2}{|c|}{ Penulisan Kata } & \multirow{2}{*}{ Total } & \multirow{2}{*}{ Ket } \\
\hline & & Kata Dasar & Kata Depan & & \\
\hline 1 & D1 & 9 & 13 & 22 & \\
\hline 2 & D2 & 23 & 7 & 30 & \\
\hline 3 & D3 & 9 & 16 & 25 & \\
\hline 4 & D4 & 9 & 7 & 16 & \\
\hline 5 & D5 & 9 & 7 & 16 & \\
\hline 6 & D6 & 9 & 15 & 24 & \\
\hline 7 & D7 & 11 & 10 & 21 & \\
\hline 8 & D8 & 3 & 11 & 14 & \\
\hline 9 & D9 & 3 & 8 & 11 & \\
\hline 10 & D10 & 14 & 6 & 20 & \\
\hline 11 & D11 & 9 & 7 & 16 & \\
\hline 12 & D12 & 11 & 5 & 16 & \\
\hline 13 & D13 & 5 & 3 & 8 & \\
\hline 14 & D14 & 17 & 6 & 23 & \\
\hline 15 & D15 & 11 & 8 & 19 & \\
\hline 16 & D16 & 5 & 4 & 9 & \\
\hline 17 & D17 & 8 & 6 & 14 & \\
\hline 18 & D18 & 8 & 5 & 13 & \\
\hline 19 & D19 & 9 & 5 & 14 & \\
\hline 20 & $\mathrm{D} 20$ & 11 & 4 & 15 & \\
\hline 21 & D21 & 8 & 6 & 14 & \\
\hline 22 & $\mathrm{D} 22$ & 3 & 6 & 9 & \\
\hline \multicolumn{2}{|c|}{ Jumlah } & 204 & 165 & 369 & \\
\hline
\end{tabular}




\section{Tabel 4}

Hasil Analisis Penulisan Kata Bahasa Indonesia

Pada Hasil Laporan Kegiatan Penerapan Perangkat Pembelajaran (P3)

\begin{tabular}{|c|c|c|c|c|}
\hline No & Data & Kalimat Efektif & Total & Ket \\
\hline 1 & D1 & 36 & 36 & \\
\hline 2 & D2 & 20 & 20 & \\
\hline 3 & D3 & 23 & 23 & \\
\hline 4 & D4 & 27 & 27 & \\
\hline 5 & D5 & 27 & 27 & \\
\hline 6 & D6 & 20 & 20 & \\
\hline 7 & D7 & 23 & 23 & \\
\hline 8 & D8 & 17 & 17 & \\
\hline 9 & D9 & 28 & 28 & \\
\hline 10 & D10 & 21 & 21 & \\
\hline 11 & D11 & 25 & 25 & \\
\hline 12 & D12 & 31 & 31 & \\
\hline 13 & D13 & 35 & 35 & \\
\hline 14 & D14 & 22 & 22 & \\
\hline 15 & D15 & 21 & 21 & \\
\hline 16 & D16 & 20 & 20 & \\
\hline 17 & D17 & 15 & 15 & \\
\hline 18 & D18 & 25 & 25 & \\
\hline 19 & D19 & 23 & 23 & \\
\hline 20 & D20 & 18 & 18 & \\
\hline 21 & D21 & 21 & 21 & \\
\hline 22 & D22 & 18 & 18 & \\
\hline \multicolumn{2}{|c|}{ Jumlah } & 516 & 516 & \\
\hline
\end{tabular}

\section{Penggunaan Huruf}

Berikut ini penjelasan secara rinci mengenai penggunaan huruf kapital, hasil laporan kegiatan Penerapan Perangkat Pembelajaran (P3).

(001) "Dengan mengucap pujisyukuratas kehadiratAllah SWT, berkat rahmat serta hidayah-Nya.."

Berdasarkan kutipan data 001 di sampinng penggunaan huruf kapital pada kata "Dengan" merupakan ketidaktepatan yang sesuai dengan PUEBI, penulisan kata tersebut tidak menggunakan huruf kapital di awal kata, kata tersebut ditulis seperti berikut "dengan".Kata "dengan" tidak dapat diletakkan di awal kalimat, dikarenakan kata tersebut merupakan konjungsi.

\section{Penggunaan Tanda Baca}

Penggunaan tanda baca, antara lain penggunaan tanda titik dan tanda koma. Berikut ini penggunaan tanda baca pada hasil laporan kegiatan Penerapan Perangkat 
Pembelajaran (P3) mahasiswa semester VIIA Program Studi Pendidikan Bahasa dan Sastra Indonesia STKIP-PGRI Lubuklinggau.

Nilai-nilai kehidupan dalam cerpendan mendemonstrasikancerpen, tujuan pelaksanaan Penerapan Perangkat (P3)

Berdasarkan pada kutipan di atas yakni "Nilai-nilai kehidupan dalam cerpendan mendemonstrasikancerpen," penggunaan tanda koma kurang tepat seharusnya menggunakan tanda titik karena lebih tepat pada kalimat yang baru. Hal ini sesuai dengan kegunaan dan fungsi tanda titik. Lain halnya dengan:

Tentunyatidaksedikitkendalayang melaksanakanKegiatanPenerapan

Dalammengatasi masalahtersebut

$$
\begin{array}{r}
\text { dihadapiolehpenulisselama } \\
\text { Perangkat Pembelajaran(P3). }
\end{array}
$$

Berdasarkan pada kutipan di samping yakni "KegiatanPenerapan Perangkat Pembelajaran(P3).Dalammengatasi masalahtersebut" penggunaan tanda titik kurang tepat seharusnya menggunakan tanda koma karena lebih tepat.Hal ini sesuai dengan kegunaan dan fungsi tanda titik.

\section{Tanda Hubung dan Tanda Titik Dua}

Penggunaan tanda baca, antara lain penggunaan tanda hubung dan tanda titik dua. Berikut ini penggunaan tanda baca pada hasil laporan kegiatan Penerapan Perangkat Pembelajaran (P3) mahasiswa semester VIIA Program Studi Pendidikan Bahasa dan Sastra Indonesia STKIP-PGRI Lubuklinggau.

\section{AKADEMIK 2018/2019}

Berdasarkan kutipan di atas, penulisan tanda hubung, tanda hubung digunakan untuk menyambung suku-suku kata dasar yang terpisah oleh pergantian baris, di sini menggunakan tanda pisah bukan tanda hubung, disertai juga menggunakan spasi pada kata. Seharusnya data 1 bukan menggunakan garis miring (/) akan tetapi seharusnya menggunakan tanda hubung (-). Hal ini sesuai dengan kegunaan dan fungsi tanda hubung. Lain halnya dengan:

(01) tersusun secarabenarterdiri atas:

Berdasarkan kutipan di atas Pada kutipan di samping tanda (:) tidak perlu diberikan jarak atau spasi, seharusnya setelah kata "atas" langsung diberikan tanda (:).Hal ini sesuai dengan kegunaan dan fungsi tanda titik koma. 


\section{Tanda Garis Miring dan Tanda Tanya}

Penggunaan tanda baca, antara lain penggunaan tanda garis miring dan tanda tanya. Berikut ini penggunaan tanda baca pada hasil laporan kegiatan Penerapan Perangkat Pembelajaran (P3) mahasiswa semester VIIA Program Studi Pendidikan Bahasa dan Sastra Indonesia STKIP-PGRI Lubuklinggau.

\section{(01)Mahasiswa yang telah melaksanakan PPL1/Microteacing}

Berdasarkan pada kutipan data 1 di atas maka dapat di katakan bahwa penggunaan tanda baca garis miring tersebut tidak tepat, karena kata ppl dan microteacing itu artinya tidak sama. Kalimat yang benar seharusnya mahasiswa yang telah melaksanakan PPL1 dan microtacing.Hal ini sesuai dengan fungsi dan kegunaan dari penggunaan tanda garis miring.

(03) Di negeri, di mana penduduknya sendiri melarat itu?

Berdasarkan kutipan di atas kurang tepat, penulisan tanda tanya karena kalimat pada kutipan itu rancu atau tidak jelas apa yang dipertanyakan. Seharusnya kalimat yang tepat yaitu di negeri mana penduduknya melarat?Hal ini sesuai dengan fungsi dan kegunaan dari penggunaan tanda Tanya.

\section{Unsur Serapan}

Analisis unsur serapan, berikut pada hasil laporan kegiatan Penerapan Perangkat Pembelajaran (P3) mahasiswa semester VIIA Program Studi Pendidikan Bahasa dan Sastra Indonesia STKIP-PGRI Lubuklinggau.

(01) memahami Nilai-nilai kehidupan dalam cerpendanmendemonstrasikancerpen, tujuan pelaksanaan Penerapan Perangkat (P3) untukmemberikan pemahamanantentang nilai-nilai kehidupan dalamcerpendanmendemonstrasikannilai-nilai kehidupandalamcerpen.

Berdasarkan Kutipan di atas diketahui bahwa kata Mendemonstrasikan terdiri dari kata men-, demonstrasi, -kan. Kata demonstrasi merupakan kata serapan dari bahasa Inggris yang berarti demontration.

\section{Kata Dasar}

Berikut ini penjelasan secara rinci mengenai analisis kata dasar, hasil laporan kegiatan Penerapan Perangkat Pembelajaran (P3) mahasiswa semester VIIA Program Studi Pendidikan Bahasa dan Sastra Indonesia STKIP-PGRI Lubuklinggau.

(001) Dengan mengucap pujisyukuratas kehadiratAllah SWT, berkat rahmat serta hidayah-Nya. 
Berdasarkan kutipan data 1 di atas kata kehadirat merupakan kata yang kurang tepat karena dalam KBBI kata kehadirat bukanlah kata yang baku dan tidak memiliki makna. Sesuai dengan KBBI kata kehadirat harusnya tidak perlu dipakai.

\section{Kata Depan}

Berikut ini penjelasan secara rinci mengenai analisis kata depan, hasil laporan kegiatan Penerapan Perangkat Pembelajaran (P3) mahasiswa semester VIIA Program Studi Pendidikan Bahasa dan Sastra Indonesia STKIP-PGRI Lubuklinggau.

(001) Rendahnya minat keterampilan berbahasa siswa berpengaruh pula pada pelajaran bahasaIndonesia dikelas.

Berdasarkan kutipan data 1 di atas tersebut penggunaan pada kata dikelas kurang tepat hal ini karena penggunaan kata tersebut seharusnya dipisahkan menjadi kata di kelas. Karena kata depan seperti di ditulis terpisah dari kata yang mengikutinya.

\section{Analisis Kalimat Efektif}

Berikut ini penjelasan secara rinci mengenai analisis kalimat efektif, hasil laporan kegiatan Penerapan Perangkat Pembelajaran (P3) mahasiswa Program Studi Pendidikan Bahasa dan Sastra Indonesia STKIP-PGRI Lubuklinggau.

(001) Berikut ini penjelasan secara rinci mengenai analisis kata depan, hasil laporan kegiatan Penerapan Perangkat Pembelajaran (P3) mahasiswa Program Studi Pendidikan Bahasa dan Sastra Indonesia STKIP-PGRI Lubuklinggau.

Berdasarkan kutipan data 1 di atas pola kalimat yang tidak sistematis, beberapa kata yang memiliki makna sama diulang, sehingga menimbulkan makna ambiguitas. Perbaikan: Laporan P3 (Penerapan Perangkat Pembelajaran) menjelaskan kegiatanBelajarMengajarBahasaIndonesiapada keterampilan membaca, berbicara, menulis, dan menyimak.

\section{PEMBAHASAN}

Kesalahan penggunaan bahasa Indonesia pada hasil laporan kegiatan Penerapan Perangkat Pembelajaran (P3) ini berkaitan dengan tiga penggunaan bahasa Indonesia diantarannya penggunaan ejaan terdiri dari penggunaan huruf, penggunaan kata, penggunaan unsur serapan dan tanda baca. Selanjutnya penggunaan pemilihan kata yang terdiri dari penggunaan kata dasar dan kata depan. Penggunaan kalimat terdiri 
(kalimat efektif). Berdasarkan hasil penelitian ini berupa analisis penggunaan bahasa Indonesia pada hasil laporan kegiatan Penerapan Perangkat Pembelajaran (P3) yang meliputi: penggunaan ejaan terdiri dari penggunaan huruf, penggunaan kata, penggunaan unsur serapan dan tanda baca. Selanjutnya penggunaan pemilihan kata yang terdiri dari penggunaan kata dasar dan kata depan. Penggunaan kalimat terdiri (kalimat efektif). Setelah dilakukan analisis pada hasil laporan kegiatan Penerapan Perangkat Pembelajaran (P3).

Berdasarkan tabel hasil kesalahan penggunaan bahasa Indonesia pada hasil laporan kegiatan Penerapan Perangkat Pembelajaran (P3) di atas, terdapat kesalahan pada penggunaan huruf dan penggunaan tanda baca. Pada penggunaan huruf terdapat tiga bagian yaitu penggunaan ejaan, penggunaan pemilihan kata dan penggunaan kalimat. Pada penggunaan huruf kapital terdapat kesalahan yang sering terjadi yaitu pada penulisan nama, kata ganti tuhan, sub judul dan daftar isi, pada penggunaan huruf kapital kesalahan yang sering terjadi yaitu pada penulisan judul buku, sedangkan pada penggunaan huruf tebal kesalahan yang sering terjadi yaitu pada penulisan sub judul, judul buku dan penulisan daftar isi.

Pada penggunaan tanda baca terdapat 5 bagian yaitu penggunaan tanda titik, penggunaan tanda koma, penggunaan tanda titik koma, penggunaan tanda titik dua, dan penggunaan tanda hubung. Pada penggunaan tanda titik terdapat kesalahan yang sering terjadi yaitu pada penulisan sub judul, akhir kalimat, dan pada penulisan bilangan, pada penggunaan tanda koma terdapat kesalahan yang sering terjadi yaitu pada penggunaan koma antara anak kalimat dan induk kalimat, pada penulisan gelar, pada penggunaan tanda titik dua terdapat kesalahan yang sering terjadi yaitu pada penulisan kitab, pada penggunaan tanda titik dua terdapat kesalahan yang sering terjadi yaitu pada penulisan pernyataan lengkap, pada penggunaan tanda hubung terdapat kesalahan yang serimg terjadi yaitu pada penulisan kitab, menuliskan kata ganti Tuhan, dan pada penulisan kata ulang yang setara.

\section{SIMPULAN}

Berdasarkan hasil penelitian dapat disimpulkan jika penggunaan Bahasa Indonesia pada hasil laporan P3 (Penerapan Perangkat Pembelajaran) masih kurang, sehingga memerlukan bimbingan lebih lanjut agar kedepanya penggunaan bahasa Indonesia bisa lebih baik. 


\section{DAFTAR PUSTAKA}

Ayudia, (2016). Analisis Kesalahan Penggunaan Bahasa Indonesia dalam Laporan Hasil Observasi pada Siswa SMP.Jurnal: BASASTRA (Penelitian Bahasa Sastra Indonesia dan Pembelajarannya), 4(1)

Chaer. (2016). Linguistik Umum. Jakarta: Rineka Cipta.

Ramaniyar. E. (2019) Penggunaan Bahasa Indonesia dalam Penulisan Artikel Ilmiah. Jurnal: Pendidikan Bahasa, 8(1)

Utomo, A.,P.,Y. (2019). Kesalahan Bahasa pada Manuskrip Artikel Mahasiswa di Jurnal Sastra Indonesia. Jurnal: Sastra Indonesia, JSI 8 (3)

Yustisia, T. V. (2015). Pedoman Umum Ejaan Bahasa Indonesia. Jakarta: Visimedia. 